Water, Air, and Soil Pollution: Focus (2007) 7: 707

\title{
ERRATUM
}

Published online: 19 September 2006

\section{DOI: 10.1023/A:1019907830132}

\section{Retraction:}

Since the appearance of the article D.F Wenderoth, P. Rosenbrock, D. Pieper and M.G. Höfle. (2002) 'Assessment of population dynamics of specific strains in groundwater bioaugmentation experiments by two different molecular techniques' by in 'Water, Air, \& Soil Pollution: Focus' Volume 2, Issues 3 (2002), pages 195203, inconsistencies in the statistical data analysis have been detected which raise doubts about the overall conclusions drawn in this publication. Therefore, we have to retract this paper.

The publisher would like to apologize for any inconvenience this may have caused. 